\title{
An Intelligent Safety Analysis Model of International Trade in China and Its Application
}

\author{
Hongyan Zuo ${ }^{1,2^{\star}}$ \\ ${ }^{1}$ School of Business, Hunan International Economics University, Changsha, China, 410205, P. R. \\ China; \\ ${ }^{2}$ Hunan province transnational investment and operations research base, Changsha, China, \\ 410205, P. R. China \\ *zuohongyan18@126.com
}

Keywords: Fuzzy support vector machines; International trade; Safety; Intelligent analysis

\begin{abstract}
An intelligent analysis model of international trade safety in China was developed based on fuzzy least squares support vector machine (FLS-SVM). The application results revealed that the intelligent analysis model is valid for improving the analysis accuracy of the data with noises or outliers and its relative errors were less than $0.8 \%$.
\end{abstract}

\section{Introduction}

Under the environment of economic globalization and accession to WTO[1-2], China has to work out better development strategy of international trade to promote the healthy adjustment of industrial structure and improve the international competitiveness of trade commodities and the safety of international trade [3]. However, how to study the safety of international trade in China effectively has become the key to improve the international competitiveness of trade commodity[4]. Historical data of the safety of China international trade needs to be distinguished based on historical materials by experts when discriminating the safety of Chinese international trade. But, more often than not, only fuzzy judgment can be given for the historical data is not comprehensive and accurate enough, which can affect experts in judge of safety assortment. The FLS-SVM [5-7] has unique advantages in solving such problems. Therefore, in this paper, the FLS-SVM is used to analyze the safety of international trade in China. And the results of intelligent safety analysis will provide strong theory and technical support for rapid and effective analysis on the safety of international trade in China.

\section{Establishment of Intelligent Safety Analysis Model of International Trade}

Evaluation Index of China International Trade Safety. As for the actual situation of China international trade, the indexes of gross fixed asset investment $x_{1}$, actual utilization of foreign investment $x_{2}$, the year-end remaining balance of urban and rural resident savings deposits $x_{3}$, foreign exchange reserve $x_{4}$, the rate of RMB to USD $x_{5}$ and money supply $x_{6}$ are selected, which are easy to obtain, show strong operability and can most reflect the current safety status of China international trade objectively.

Gross Fixed Asset Investment X1. The investment of fixed assets can lead to the adjustment of industrial structure in China, improve the investment environment and enhance the competitiveness of domestic enterprises, having a relatively direct and obvious impact on total foreign trade volume.

Actual Utilization of Foreign Investment X2. The actual utilization of foreign investment includes foreign loan, direct foreign investment and other foreign investments. As long as the trend of foreign investment in manufacturing industry of China remains unchanged, the import and export of China will continue to maintain high-speed growth.

The Year-End Remaining Balance of Urban and Rural Resident Savings Deposits X3. The year-end remaining balance of urban and rural resident savings deposits represents the purchasing power of the domestic market, to some extent, and affects the trade volume. 
Foreign Exchange Reserve X4. The main purpose of foreign exchange reserve is to pay off the international payment deficit, which is also used to intervene in the foreign exchange market frequently to maintain the currency exchange rate of this country, primarily related to foreign trade directly.

The Rate of RMB to USD X5. The increase of the rate of RMB to USD will result in RMB devaluation and price reduction of Chinese export commodity, but the international competitiveness of foreign trade will strengthen, the exports increase and imports reduce, then the net export value will increase. In contrast, when the exchange rate reduces, RMB will appreciate, the international competitiveness of Chinese export commodity will weaken, the exports reduce and imports increase, which is not conducive to the increase of international balance of payments. Therefore, the exchange rate plays a vital role in the foreign trade of China.

Money Supply X6. Money supply has a positive impact on the growth of export and import, which can promote the domestic market demand effectively and promote the demand of domestic enterprises and residents for foreign capital and products. In addition, the growth of export and import will inhibit the growth of money supply.

Fuzzy Least Squares Support Vector Machines. Based on the FLS-SVM, the fuzzy samples of input for safety status prediction of China international trade can be expressed as:

$\left(x_{1}, y_{1}, \mu\left(x_{1}\right)\right),\left(x_{2}, y_{2}, \mu\left(x_{2}\right)\right), \ldots,\left(x_{k}, y_{k}, \mu\left(x_{k}\right)\right), k=1,2, \ldots, 6$

Where $\mu\left(x_{k}\right)$ is the membership, $0<\mu\left(x_{k}\right) \leqslant 1$

The intelligent safety analysis model of international trade in China based on the FLS-SVM is shown in Fig. 1.

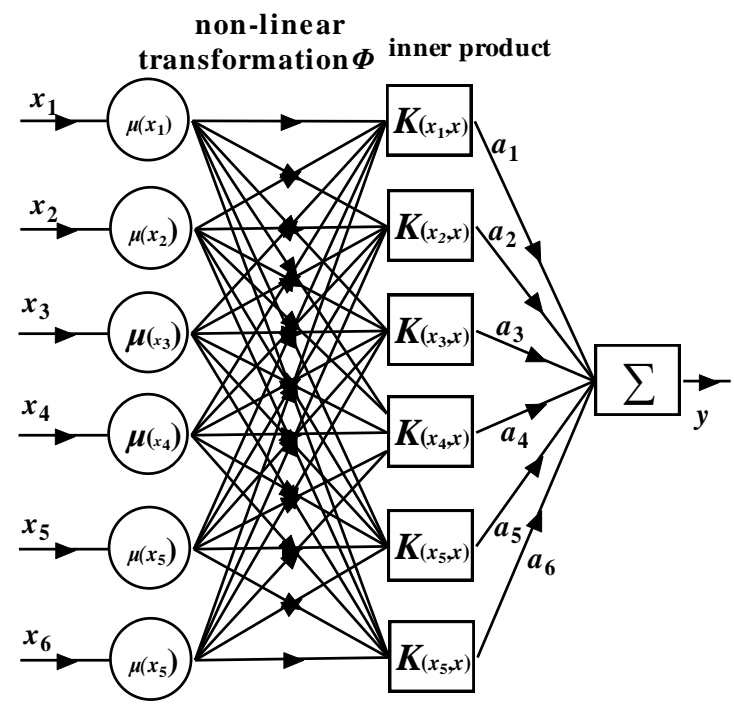

Figure 1. Intelligent safety analysis model of China international trade

By fuzzy membership, the optimal hyper plane of the FLS-SVM is the optimal solution of the objective function shown in Eq. (3):

$\min J(w, \xi)=\frac{1}{2} w^{\mathrm{T}} \cdot w+\frac{C}{2} \sum_{i=1}^{6} \mu\left(x_{i}\right) \cdot \varepsilon_{i}^{2}$

s.t. $y_{i}=w^{T} \cdot \phi\left(x_{i}\right)+b+\varepsilon_{i}, \varepsilon_{i}>0, \quad i=1,2, \ldots, 6$.

Where $\varepsilon_{i}$ is slack variable; $C$ is penalty factor; $b$ is the threshold value.

Corresponding Lagrange function is:

$$
L=J-\sum_{i=1}^{6} a_{i}\left[w^{T} \cdot \varphi\left(x_{i}\right)+\varepsilon_{i}+b-y_{i}\right] \quad \mathrm{i}=1,2 \ldots 6
$$

Where $a_{i}$ is the Lagrange coefficient. 
The optimization problem of the FLS-SVM is transformed into a problem of solving linear equation:

$\left[\begin{array}{cc}0 & E^{T} \\ E & \Omega+6 C \cdot \mu\left(x_{i}\right)^{-1}\end{array}\right]\left[\begin{array}{l}b \\ a\end{array}\right]=\left[\begin{array}{l}0 \\ y\end{array}\right]$

where $\boldsymbol{y}=\left[y_{1}, y_{2}, \ldots, y_{6}\right]^{\mathrm{T}} ; \boldsymbol{E}=[1,1, \ldots, 1]^{\mathrm{T}}, \boldsymbol{a}=\left[a_{1}, a_{2}, \ldots, a_{6}\right]^{\mathrm{T}} ; \Omega_{i j}=\varphi\left(x_{i}\right)^{\cdot} \varphi\left(x_{j}\right)=K\left(x_{i}, x_{j}\right)$.

Then the safety analysis model of international trade in China based on the FLS-SVM is expressed as follow.

$$
y(x)=\sum_{i=1}^{6} a_{i} K\left(x_{i}, x\right)+b
$$

Where $\boldsymbol{x}=\left[x_{1}, x_{2}, \ldots, x_{6}\right], K\left(x_{i}, \boldsymbol{x}\right)=\exp \left\{-\left|x_{i}-\boldsymbol{x}\right|^{2} / \sigma^{2}\right\}, \sigma$ is kernel parameter.

\section{Application of Intelligent Safety Analysis Model of International Trade}

Grade Division of International Trade Safety in China. The output parameters of intelligent analysis model of China international trade safety based on the FLS-SVM are safety grades of China international trade, which are divided into five grades. The five grades values of the desired output of intelligent analysis model on China international trade safety based on the FLS-SVM are in the following order: Grade $\mathrm{A}$ (very insecure): $R_{1}=(1,0,0,0,0)$; Grade $\mathrm{B}$ (less secure) $; R_{2}=(0,1,0,0,0)$; Grade C(general secure): $R_{3}=(0,0,1,0,0)$; Grade $\mathrm{D}$ (relatively secure) $: R_{4}=(0,0,0,1,0)$; Grade $\mathrm{E}$ (very secure) : $R_{5}=(0,0,0,0,1)$. Therefore, the output parameters of intelligent analysis model of China international trade safety based on the FLS-SVM are values of China international trade safety grade $R_{i}(i=1,2,3,4,5)$.

Intelligent Safety Analysis on International Trade in China. Index parameters of China international trade safety from 1980 to 2014 are shown in Table 1, data from 1980 to 2006 are set as training sample sets while data from 2007 to 2014 as the test samples for the intelligent analysis of China international trade safety. The historical materials are not comprehensive enough and historical data is not accurate enough, which will affect expert in judge of safety grade $R_{i}$. Therefore, only fuzzy judgment of China international trade safety $R_{j}$ from 1980 to 2014 can be given by experts according to the total value of historical import and export trade as shown in Table1.

Table 1 Index parameters $\mathrm{xi}(\mathrm{i}=1,2, \ldots, 6)$ of China international trade safety

\begin{tabular}{|c|c|c|c|c|c|c|c|}
\hline Year & $x_{1} / \Varangle 0.1$ Billion & $x_{2} / \$ 0.1$ Billion & $x_{3} / ¥ 0.1$ Billion & $\begin{array}{c}x_{4} / \$ 0.1 \\
\text { Billion }\end{array}$ & $x_{5} / 1$ & $x_{6} / ¥ 0.1$ Billion & $R_{j}$ \\
\hline 1980 & 2983 & 15 & 399.5 & -13 & 1.4984 & 300.41 & $R_{5}$ \\
\hline 1981 & 961 & 25 & 523.7 & 27.1 & 1.705 & 415.03 & $R_{5}$ \\
\hline$\vdots$ & $\vdots$ & $\vdots$ & $\vdots$ & $\vdots$ & $\vdots$ & $\vdots$ & $\vdots$ \\
\hline 2011 & 311485.13 & 1150.5 & 34363509 & 31811.5 & 6.4588 & 41600 & $R_{3}$ \\
\hline 2012 & 364835 & 1117.2 & 399551 & 33116 & 6.3125 & 974159.5 & $R_{2}$ \\
\hline 2013 & 447074 & 1175.86 & 447602 & 38213 & 6.1923 & 1106500 & $R_{2}$ \\
\hline 2014 & 502005 & 1195.6 & 503000 & 38430 & 6.2166 & 1228400 & $R_{2}$ \\
\hline
\end{tabular}

To validate the validity of intelligent safety analysis model(denoted by F1 Model) of international trade in China based on the FLS-SVM, the data as shown in Table 1 is used for simulation experiment and its intelligent analysis result is compared with intelligent analysis model of the literature[7](denoted by F2 Model). 
Taking the China international trade safety $R_{j}(j=1,2, \ldots, 5)$ as the output of the FLS-SVM and the index parameters ( gross fixed asset investment $x_{1}$, actual utilization of foreign investment $x_{2}$, the year-end remaining balance of urban and rural resident savings deposits $x_{3}$, foreign exchange reserves $x_{4}$, the rate of RMB to USD $x_{5}$ and money supply $x_{6}$ ) from 1980 to 2006 as the input of the FLS-SVM, the intelligent safety analysis values and actual values of China international trade from 1980 to 2006 will be obtained in Table 2, the relative error of the training results for intelligent analysis model is less than $0.7 \%$. Obviously, prediction accuracy of F1 Model is higher than that of F2 Model.

Taking the China international trade safety $R_{j}(j=1,2, \ldots, 5)$ as the output of the FLS-SVM and the index parameters from 2007 to 2014 as the input of the FLS-SVM, the intelligent safety analysis values and actual values of China international trade from 2007 to 2014 will be obtained in Table 3, the relative error of the training results for intelligent analysis model is less than $0.9 \%$.

Table 2 Intelligent analysis model training results of China international trade safety

\begin{tabular}{|c|c|c|c|c|c|}
\hline Year & \multirow{2}{*}{$\begin{array}{c}\text { Desired output } \\
\text { values }\end{array}$} & \multicolumn{2}{|c|}{ Actual output $\times 100$} & \multicolumn{2}{c|}{ Error /\% } \\
\cline { 3 - 6 } & & Model F2 & Model F1 & Model F2 & Model F1 \\
\hline 1980 & $R_{5}(0,0,0,0,1)$ & $(0.12,0.22,0.11,0.16,98.02)$ & $(0.06,0.06,0.08,0.12,99.45)$ & 1.98 & 0.55 \\
\hline 1981 & $R_{5}(0,0,0,0,1)$ & $(0.33,0.41,0.26,0.27,98.43)$ & $(0.08,0.11,0.16,0.12,99.47)$ & 1.57 & 0.53 \\
\hline$\vdots$ & $\vdots$ & $\vdots$ & $\vdots$ & $\vdots$ & $\vdots$ \\
\hline 2004 & $R_{5}(0,0,0,1,0)$ & $(0.89,0.92,0.53,0.65,98.49)$ & $(0.21,0.14,0.22,0.26,99.54)$ & 1.51 & 0.46 \\
\hline 2005 & $R_{3}(0,0,1,0,0)$ & $(0.59,0.76,98.45,0.75,0.61)$ & $(0.22,0.28,99.39,0.31,0.23)$ & 1.55 & 0.61 \\
\hline 2006 & $R_{3}(0,0,1,0,0)$ & $(0.78,0.64,98.42,0.77,0.95)$ & $(0.21,0.22,99.48,0.17,0.23)$ & 1.58 & 0.52 \\
\hline
\end{tabular}

Table 3 Intelligent analysis model test results of China international trade safety after training

\begin{tabular}{|c|c|c|c|c|c|}
\hline \multirow{2}{*}{ Year } & Desired output & \multicolumn{2}{|c|}{ Actual output $\times 100$} & \multicolumn{2}{c|}{ Error /\% } \\
\cline { 3 - 6 } & & Model F2 & Model F1 & Model F2 & Model F1 \\
\hline 2007 & $R_{3}(0,0,1,0,0)$ & $(0.48,0.56,98.45,0.45,0.62)$ & $(0.17,0.18,99.25,0.18,0.22)$ & 1.35 & 0.75 \\
\hline 2008 & $R_{2}(0,1,0,0,0)$ & $(0.91,98.67,0.83,0.54,0.63)$ & $(0.18,99.34,0.18,0.26,0.23)$ & 1.33 & 0.66 \\
\hline$\vdots$ & $\vdots$ & $\vdots$ & $\vdots$ & $\vdots$ & $\vdots$ \\
\hline 2013 & $R_{1}(1,0,0,0,0)$ & $(98.23,0.86,0.89,1.12,0.98)$ & $(99.25,0.21,0.22,0.28,0.25)$ & 1.77 & 0.75 \\
\hline 2014 & $R_{2}(0,1,0,0,0)$ & $(0.91,98.12,0.83,0.54,0.63)$ & $(0.18,99.15,0.18,0.26,0.23)$ & 1.88 & 0.85 \\
\hline
\end{tabular}

The partial derivative $\gamma_{i}$ of the output to input component of the FLS-SVM is taken as the criterion of influence degree of influencing factors on China international trade safety, the greater the partial derivative is, the more remarkable the influence of the factor is, and the influencing factors calculation results of each index parameter influencing on China international trade safety are shown in Fig. 2, from which it can be seen that the influencing factor of gross fixed asset investment $\gamma_{1}>$ the influencing factor of money supply $\gamma_{6}>$ the influencing factor of rate of RMB to USD $\gamma_{5}>$ the influencing factor of actual utilization of foreign investment $\gamma_{2}>$ the influencing factor of foreign exchange reserves $\gamma_{4}>$ the influencing factor of the year-end remaining balance of urban and rural resident savings deposits $\gamma_{3}$. 


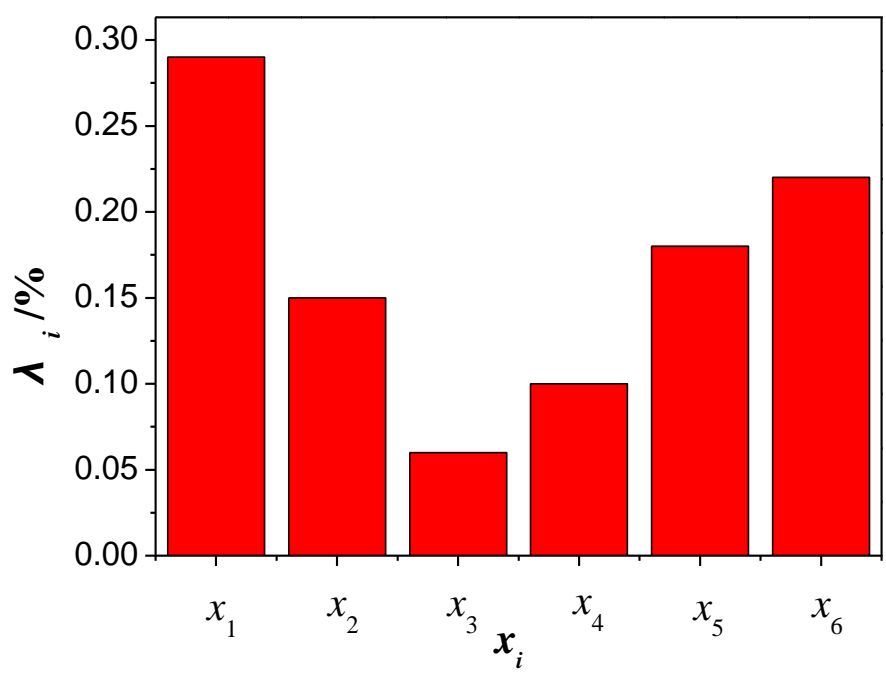

Figure 2. Influencing factors of index parameters of China international trade safety.

The reasons may be provided as follows: the growth of gross fixed asset investment could largely promote the development of China international trade, the greater domestic gross fixed asset investment is, the export is more able to be stimulated and China international trade safety is influenced more greatly; money supply can effectively promote domestic market demand, thereby to some extent, promote the growth of import and export trade, which brings relatively great impact on China international trade safety; the impact of the rate of RMB to USD is less significant than that of the gross fixed asset investment $x_{1}$ and money supply $x_{6}$, mainly because that changes in the exchange rate of RMB to USD will lead to changes in export demand of a country, that is, the reselection of export market and the rate appreciation of RMB to USD may lead to an increase of export volume to the depreciation region, therefore the influence of the rate of RMB to USD on changes of China international trade safety is not significant.

\section{Conclusions}

The application results reveal that the intelligent safety analysis model of China international trade based on the FLS-SVM can effectively improve the identification precision of data in the dataset with noisy points and anomalous points and the relative error of intelligent analysis is less than $0.8 \%$.

The factors influencing China international trade safety, influence degree of which is from big to small, are gross fixed asset investment x1, money supply x6, the rate of RMB to USD x5, actual utilization of foreign investment $\mathrm{x} 2$, foreign exchange reserves $\mathrm{x} 4$ and the year-end remaining balance of urban and rural resident savings deposits $\mathrm{x} 3$.

\section{Acknowledgements}

The authors would like to acknowledge Project(14K055) supported by Hunan province innovation platform open fund, Project(13JD31) supported Social Science Foundation of Hunan Province and Project(71573082) supported by the National Natural Science Foundation of China.

\section{References}

[1] K. Bhattacharya, G. Mukherjee, J. Saramäki, K. Kaski, S. S. Manna, The International Trade Network: weighted network analysis and modelling, Journal of Statistical Mechanics-Theory and Experiment 41(2008) 139-147.

[2] R. Kali, F. Mendez, J. Reyes, Trade structure and economic growth, Journal of International Trade \& Economic Development 16(2) (2007) 245-269. 
[3] R. Kali, J. Reyes, The architecture of globalization: A network approach to international economic integration, Journal of International Business Studies 38(5) (2007) 595-620.

[4] Hongyan Zuo. Chaos analysis on export trade system of mechanical and electrical products in China. Chengdu: 2015 International Conference on Management Science and Engineering, DEStech Publication Inc, 2016: 28-33.

[5] Hongyan Zuo, Zhouquan Luo, Jialin Guan, Yiwei Wang, Identification on rock and soil parameters for vibration drilling rock in metal mine based on fuzzy least square support vector machine, Journal of Central South University 21(3) (2014) 1085-1090.

[6] Taosheng Wang, Hongyan Zuo, Fuzzy least squares support vector machines soft measurement model based on adaptive mutative scale chaos immune algorithm, Journal of Central South University 21(2) (2014) 593-599.

[7] Vapnik V. Statistical learning theory, New York: Wiley, 1998. 